\title{
Transient Characteristics of a New Simplified Speed Sensorless Vector Control for Induction Motors
}

\author{
G. M. C. Mangindaan, M. Tsuji, S. Hamasaki \\ Graduate School of Engineering, Nagasaki University, Japan \\ E-mail: bb52212201@cc.nagasaki-u.ac.jp
}

\begin{abstract}
This paper presents a new simplified sensorless speed control method of induction motors (IM). The output voltage of $d$-axis PI current controller is used to compute the flux angle and to control the speed in correspondence with its reference. The effectiveness of the proposed method has been demonstrated by root loci and experiments. Especially the proposed method can stabilize the system at low speed regenerating operations.
\end{abstract}

Index Terms - $d$-axis voltage, root loci, speed sensorless vector control, stability

\section{INTRODUCTION}

In order to improve the performance of induction motor control without speed sensor, many sensorless vector control methods of IM have been proposed to control the torque and speed [1] - [6]. However, the systems are relatively complicated. For example, a model reference adaptive system (MRAS) based methods needs a state observer and many PI controllers $(d-q$ currents, speed and speed estimation). Furthermore, the systems may become unstable at low speed regenerating operations.

In this paper, we present a new simplified sensorless vector control method of IM. A linear model of the proposed system is derived in state space equation by taking a small perturbation of steady state operating point. Stability analysis is performed by showing root loci of the linear model. By the stability analysis we can determine the gains of controller. From the results of root loci, the unstable region of regenerating operation is removed.

Transient responses of the non-linear model are compared with those of experiment. The effectiveness of the proposed method has been demonstrated by these simulations and experiments.

\section{PRoposed METHOD}

In this section, in order to simplify the controller and to stabilize the system at low speed regenerating operations, we propose a new sensorless vector control method shown in Fig.1.

By neglecting the derivative of current and $d$-axis flux, the following $d$-axis voltage model equation is obtained in rotating reference frame.

$$
e_{s d}^{*}=R_{s}^{*} i_{s d}^{*}-\omega^{*} \sigma L_{s} i_{s q}-\omega^{*} M \psi_{r q}^{v} / L_{r}
$$

By using the $e_{d}^{*}$ which is the output of $d$-axis PI current controller in Fig.1, we have:

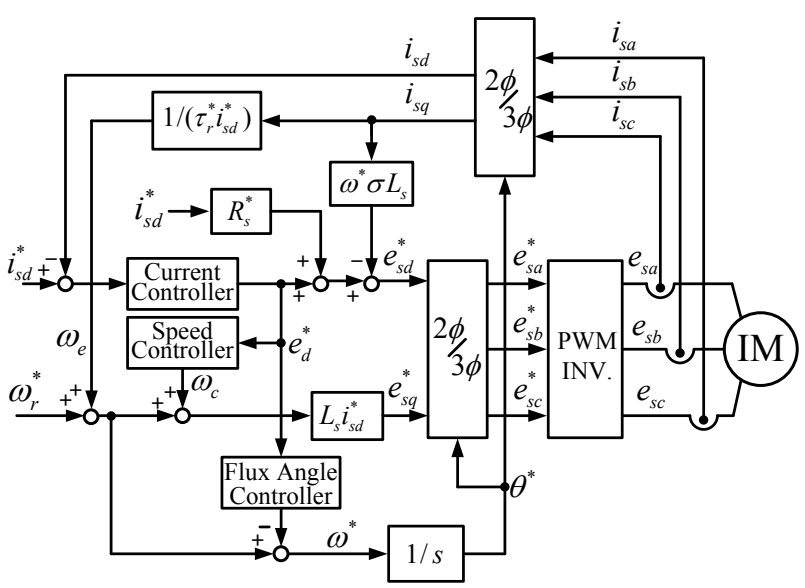

Fig.1. Block diagram of proposed method.

$$
e_{d}^{*}=-\omega^{*} M \psi_{r q}^{v} / L_{r}
$$

We estimate the flux frequency $\omega^{*}$ so as to bring $q-$ axis flux $\psi_{r q}^{v}$ zero by using flux angle controller shown in Fig.2. Slip frequency $\omega_{e}$ is added to speed command. The speed controller computes the frequency $\omega_{c}$ that controls torque and speed. In steady state, $\psi_{r q}^{v}$ must be zero by the integral control of the speed controller. Then the following relation is valid in steady state.

$$
\omega^{*}=\omega_{r}^{*}+\omega_{e}
$$

where, $\omega_{e}=\frac{i_{s q}}{\tau_{r}^{*} i_{s d}^{*}}$

When (3) is satisfied, the rotor speed is equal to its command. Flux angle $\theta^{*}$ is obtained by integrating $\omega^{*}$ as:

$$
\theta^{*}=\omega^{*} / s
$$

The $q$-axis voltage $e_{s q}^{*}$ is computed by neglecting the voltage drop of stator resistance, but it is compensated by $\omega_{c}$. In proposed system of Fig. 1, any observer is not used and the system is easily implemented.

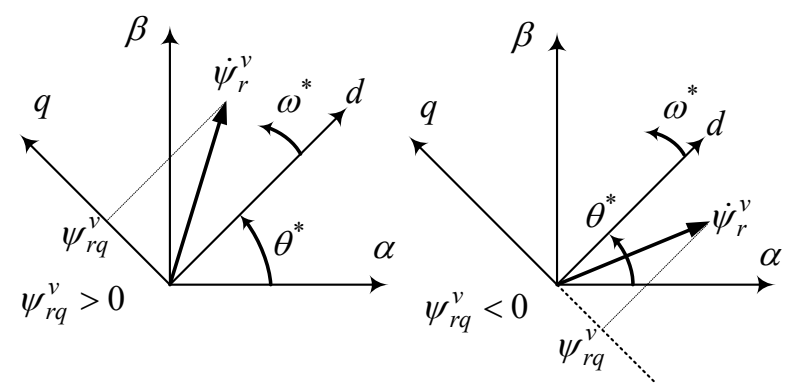

Fig.2. Flux angle estimation 


\section{ANALYTICAL MODEL}

The controllers used in Fig.1 are described as follows: Current controller:

$$
e_{d}^{*}=\left(K_{p}+\frac{K_{i}}{s}\right)\left(i_{s d}^{*}-i_{s d}\right)
$$

Speed controller:

$$
\omega_{c}=\left(K_{p c}+\frac{K_{i c}}{s}\right) e_{d}^{*}
$$

Flux angle controller:

$$
\omega^{*}=\omega_{r}^{*}+\omega_{e}-K_{\omega} e_{d}^{*}
$$

where, $K_{\omega}=\operatorname{sign}\left(\omega^{*}\right)\left|K_{\omega}\right|$.

By using the $d-q$ model of IM and the equations of proposed controller, a non-linear state equation is obtained:

$$
p \boldsymbol{x}=\boldsymbol{f}\left(\boldsymbol{x}, i_{s d}^{*}, \omega_{r}^{*}, T_{L}\right)
$$

where, $\boldsymbol{x}=\left[i_{s d} i_{s q} \psi_{r d} \psi_{r q} \omega_{r} e_{c d} \omega_{c i}\right]^{T}$

The state variables $e_{c d}$ and $\omega_{c i}$ are necessary for PI current controller and PI speed controller respectively. The transient responses of non-linear model are computed by solving (8).

We derive a linear model to study the stability of proposed system. A linear model of proposed system is derived by considering small perturbation about a steadystate operating point:

$$
p \Delta \boldsymbol{x}=\boldsymbol{A} \Delta \boldsymbol{x}+\boldsymbol{B} \Delta \omega_{r}^{*}+\boldsymbol{B}_{L} \Delta T_{L}
$$

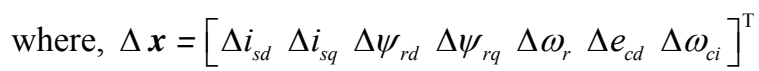

$$
a_{1}=\frac{R_{s}}{\sigma L_{s}}+\frac{M^{2}}{\sigma L_{s} L_{r} \tau_{r}}, a_{2}=\frac{M p^{2}}{4 J L_{r}}
$$

$$
\mathbf{A}=\left[\begin{array}{ccc}
-a_{1}-\frac{K_{p}}{\sigma L_{s}} & 0 & \frac{M}{\sigma L_{s} L_{r} \tau_{r}} \\
-\omega^{*}-i_{s d} K_{\omega} K_{p}\left(\frac{K_{p c}}{\sigma}+1\right) & -a_{1}+\frac{1}{\sigma \tau_{r}^{*}}-\frac{1}{\tau_{r}^{*}} & -\frac{M \omega_{r}}{\sigma L_{s} L_{r}} \\
\frac{M}{\tau_{r}}+K_{\omega} K_{p} \psi_{r q} & \frac{\psi_{r q}}{\tau_{r}^{*} i_{s d}^{*}} & -\frac{1}{\tau_{r}} \\
-K_{\omega} K_{p} \psi_{r d} & \frac{M}{\tau_{r}}-\frac{\psi_{r d}}{\tau_{r}^{*} i_{s d}^{*}} & -\left(\omega^{*}-\omega_{r}\right) \\
-a_{2} \psi_{r q} & a_{2} \psi_{r d} & a_{2} i_{s q} \\
-K_{i} & 0 & 0 \\
-K_{\omega} K_{i c} K_{p} & 0 & 0
\end{array}\right.
$$

$$
\left.\begin{array}{cccc}
\frac{M \omega_{r}}{\sigma L_{s} L_{r}} & \frac{M \psi_{r q}}{\sigma L_{s} L_{r}} & \frac{1}{\sigma L_{s}} & 0 \\
\frac{M}{\sigma L_{s} L_{r} \tau_{r}} & -\frac{M \psi_{r d}}{\sigma L_{s} L_{r}} & \frac{i_{s d}^{*} K_{\omega} K_{p c}}{\sigma}+K_{\omega} i_{s d} & \frac{i_{s d}^{*}}{\sigma} \\
\omega^{*}-\omega_{r} & -\psi_{r q} & -\psi_{r q} K_{\omega} & 0 \\
-\frac{1}{\tau_{r}} & \psi_{r d} & \psi_{r d} K_{\omega} & 0 \\
-a_{2} i_{s d} & 0 & 0 & 0 \\
0 & 0 & 0 & 0 \\
0 & 0 & K_{\omega} K_{i c} & 0
\end{array}\right]
$$$$
\mathbf{B}=\left[\begin{array}{c}
0 \\
\frac{i_{s d}^{*}}{\sigma}-i_{s d} \\
\psi_{r q} \\
-\psi_{r d} \\
0 \\
0 \\
0
\end{array}\right] \mathbf{B}_{L}=\left[\begin{array}{c}
0 \\
0 \\
0 \\
0 \\
-\frac{P}{2 J} \\
0 \\
0
\end{array}\right]
$$

We confirmed that the transient responses of the linear model are in good agreement with those of the non-linear model around the steady state operating point.

\section{TRANSIENT CHARACTERISTICS}

The proposed control system is implemented by a DSP (TMS320C32)-based PWM inverter. A compensating method is developed for the experimental system for dead time and the non-ideal features of IGBT [7]. Parameters of IM are: number of pole $P=4$, stator resistance $R_{s}$ $=1.54 \Omega$, rotor resistance $R_{r}=0.787 \Omega$, stator and rotor inductance $L_{s}=L_{r}=0.0115 \mathrm{H}$, mutual inductance $M=0.11 \mathrm{H}$, and moment of inertia $J=0.0126 \mathrm{kgm}^{2}$.

Fig 3 shows the root trajectories computed by the linear model. The speed command $N_{r}^{*}$ is $100 \mathrm{~min}^{-1}$ in case (a), $25 \mathrm{~min}^{-1}$ in case (b) and slip speed $N_{s l}$ is changed from $-80 \mathrm{~min}^{-1}$ to $80 \mathrm{~min}^{-1}$ as a parameter of load. It is demonstrated that the system is stable at low speed regenerating operation. However, the system is unstable at plugging region as shown in (b).

Fig.4 shows the unstable operating region when speed command and slip speed are changed with parameters $\left|K_{\omega}\right|=5.0$, and $K_{i c}=20.0$. The increasing value of speed control proportional gain $K_{p c}$ can improve the stability region at low speed of regenerating and motoring operations. In earlier paper, we have only studied when $K_{p c}=0.0[8]$. 
To study the stable region at low speed, we decreased the speed control integral gain $K_{i c}=5.0$ as shown in Fig.5. By comparing the unstable regions of Fig.4 with those of Fig.5, the smaller value of $K_{i c}$ can expand stable region at the plugging region. However, the unstable region at regenerating mode increases by choosing smaller $K_{i c}$. Therefore the unstable region can be minimized by changing the gain $K_{i c}$ at $\omega^{*}=0$.

The simulation results of non-linear model from each parameters of $K_{p c}$ when the speed command is changed from $100 \mathrm{~min}^{-1}$ to $200 \mathrm{~min}^{-1}$ and then to $100 \mathrm{~min}^{-1}$ can be seen in Fig.6. The speed responses can be faster by choosing large $K_{p c}$. However, a damped oscillation is observed when $K_{p c}=2.0$. Fig. 7 shows the experimental results corresponding to the simulation results of Fig.6. It is confirmed that the experimental results agree well with the theoretical results except for high frequency ripples. The high frequency ripples are caused by PWM voltage control in experimental system.

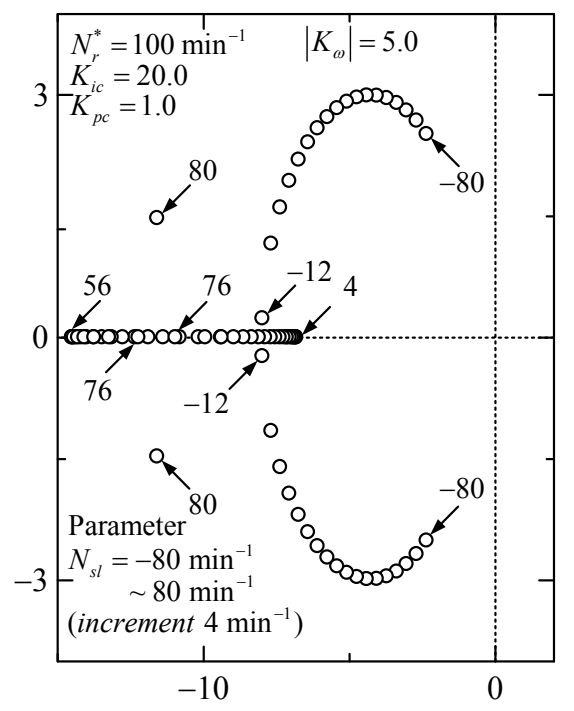

(a) $N_{r}^{*}=100 \min ^{-1}$

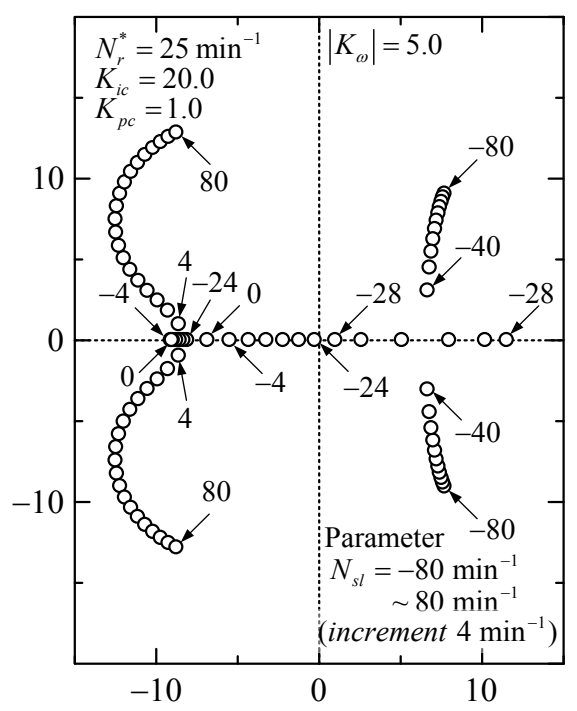

(b) $N_{r}^{*}=25 \mathrm{~min}^{-1}$.

Fig.3. Trajectories of poles obtained by linear model.

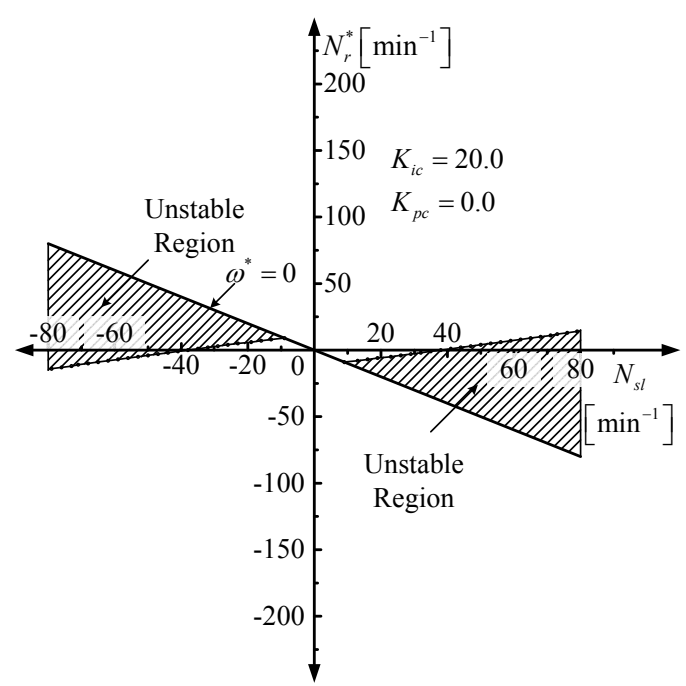

(a) $K_{p c}=0.0$

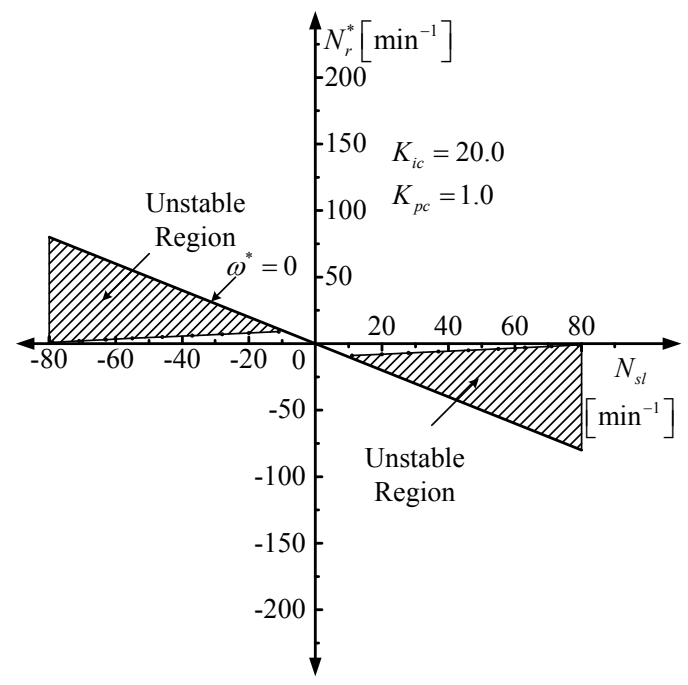

(b) $K_{p c}=1.0$

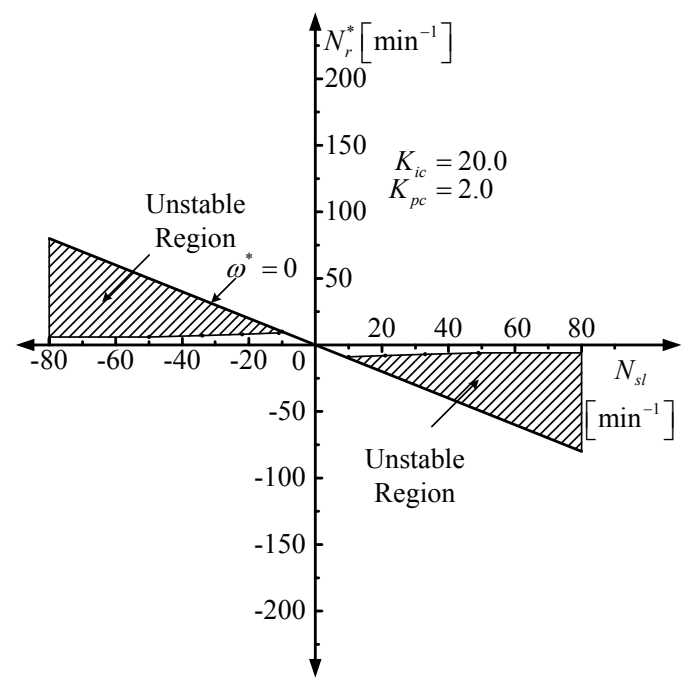

(c) $K_{p c}=2.0$

Fig.4. Unstable region with parameters $\left|K_{\omega}\right|=5.0$ and $K_{i c}=20.0$. 


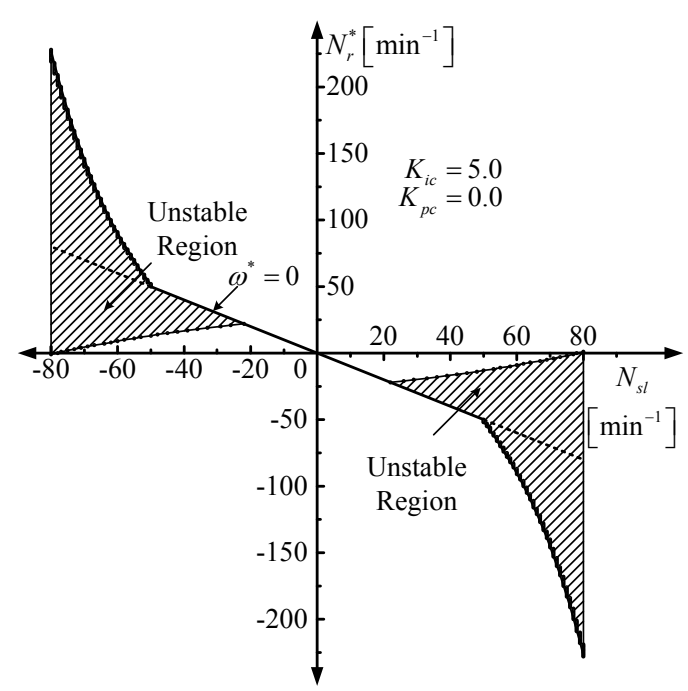

(a) $K_{p c}=0.0$

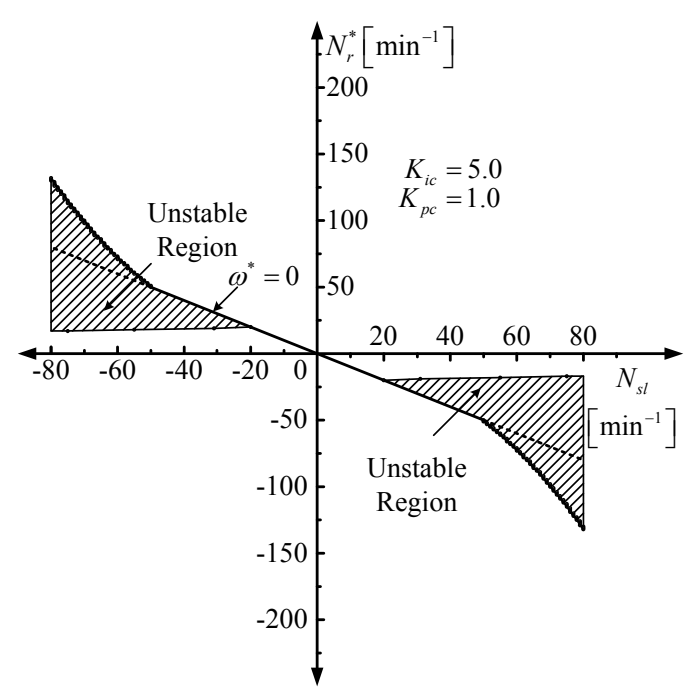

(b) $K_{p c}=1.0$

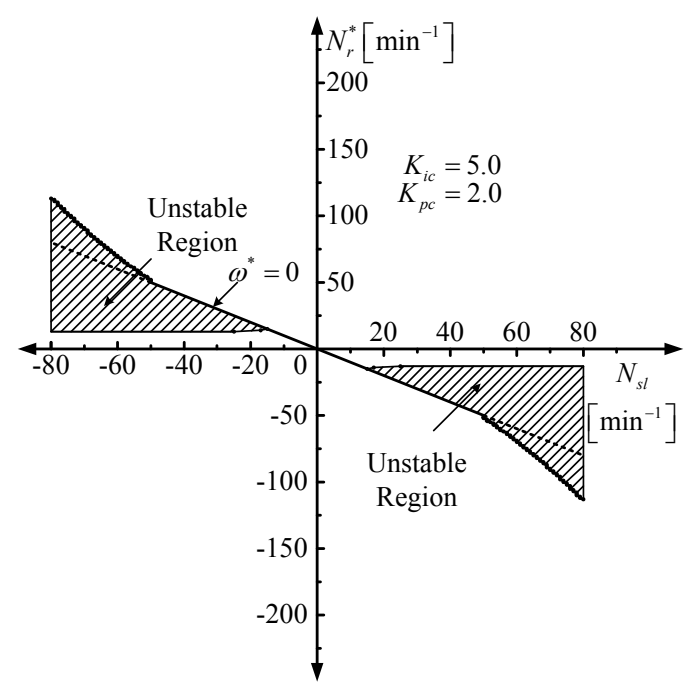

(c) $K_{p c}=2.0$

Fig.5. Unstable region with parameters $\left|K_{\omega}\right|=5.0$ and $K_{i c}=5.0$.
The good performance is obtained when $K_{p c}=1.0$, $K_{i c}=20.0$, and $\left|K_{\omega}\right|=5.0$ as shown in (b).

When the speed command is changed from $25 \mathrm{~min}^{-1}$ to $125 \mathrm{~min}^{-1}$ and then back to $25 \mathrm{~min}^{-1}$, are shown in Figs. 8 and 9. Fig.8 shows the simulation results and corresponding experimental results are shown in Fig.9. Good correlation between simulation results and experimental ones are observed. From the viewpoints of the quick response and overshoot of speed, the case (b) is desirable than cases (a) and (c). Therefore, the gains are designed as $K_{p c}=1.0, K_{i c}=20.0$, and $\left|K_{\omega}\right|=5.0$.

\section{CONCLUSIONS}

We have discussed the transient characteristics of a new simplified sensorless vector control method of IM. The results obtained from this study are summarized as follows:

(1) P control for flux angle computation and PI control for torque and speed are constructed by using the output voltage of $d$-axis current controller.

(2) The unstable regions computed by using a linear model to design the control gains.

(3) By adding $\mathrm{P}$ control for speed controller, the unstable region of plugging operation can be improved.

(4) The proposed system can realize stable operation in both motoring and regenerating modes.

(5) The experimental results agree well with those of nonlinear simulation except for high frequency ripples.

\section{REFERENCES}

[1] C. Schauder, "Adaptive speed identification for vector control of induction motors without rotational transducers", IEEE Trans. Industr. Applic., Vol.28, No.5, pp. 1054-1061, Sep./Oct. 1992.

[2] H. Tajima, Y. Hori, "Speed sensorless field orientation control of the induction machine." IEEE IAS Annual Meeting, pp. 385-391, 1991.

[3] H. Kubota, K. Matsuse, "Speed sensorless field oriented control of induction machines using flux observer", IEEE IECON, pp. 1611-1615, 1994.

[4] H. Sugimoto, L. Ding, "A consideration about stability of vector controlled induction motor systems using adaptive secondary flux observer", Trans. IEEJapan, Vol.119-D, No.10, pp.1212-1222, 1999.

[5] M. Tursini, R. Petrella, and F. Parasiliti, "Adaptive sliding mode observer for speed sensorless control of induction motors", IEEE Trans. Industr. Applic., Vol.36, No.5, pp.1380-1387, Sep./Oct. 2000.

[6] Y. Kinpara, M. Koyama, "Speed sensorless vector control method of induction motor including a low speed region", Trans. IEEJapan, Vol.120-D, No.2, pp.223-229, 2000.

[7] M. Tsuji, S. Chen, K. Izumi and E. Yamada, "A sensorless vector control system for induction motors using q-axis flux with stator resistance identification", IEEE Trans. Industrial Electronics, Vol.48, No.1, pp. 185-194, February 2001.

[8] M. Tsuji, G. M. C. Mangindaan, Y. Kunizaki, R. Hashimoto, S. Hamasaki, "A new simplified sensorless speed control of induction motor using $d$-axis voltage", Proc. Of The $15^{\text {th }}$ International Conference on Electrical Machines and Systems (ICEMS), LS4B-1, pp.1-6, 2012. 


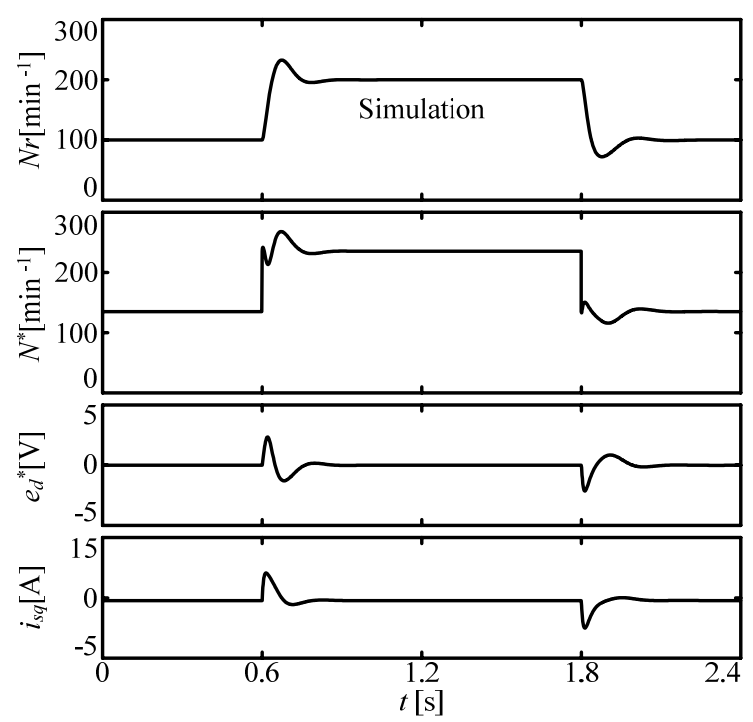

(a) $K_{p c}=0.0$
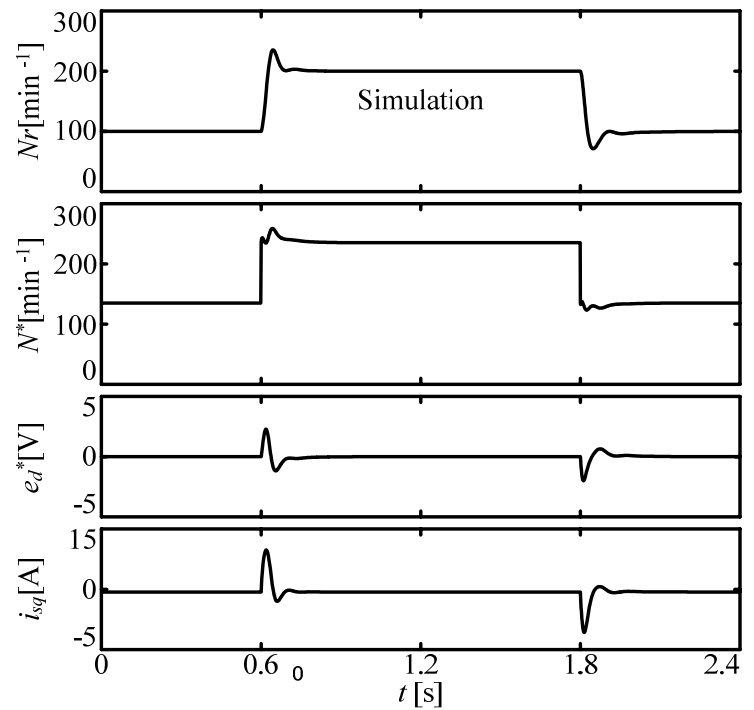

(b) $K_{p c}=1.0$
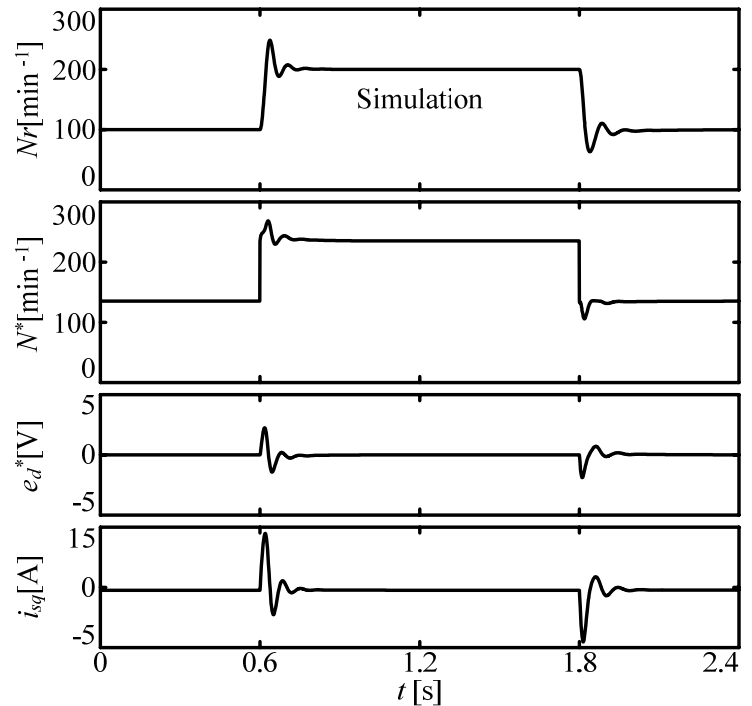

(c) $K_{p c}=2.0$

$\left(100 \rightarrow 200 \rightarrow 100 \mathrm{~min}^{-1}, T_{L}=4 \mathrm{~N}-\mathrm{m},\left|K_{\omega}\right|=5.0, K_{i c}=20.0\right)$ Fig.6. Transient responses of non-linear model.

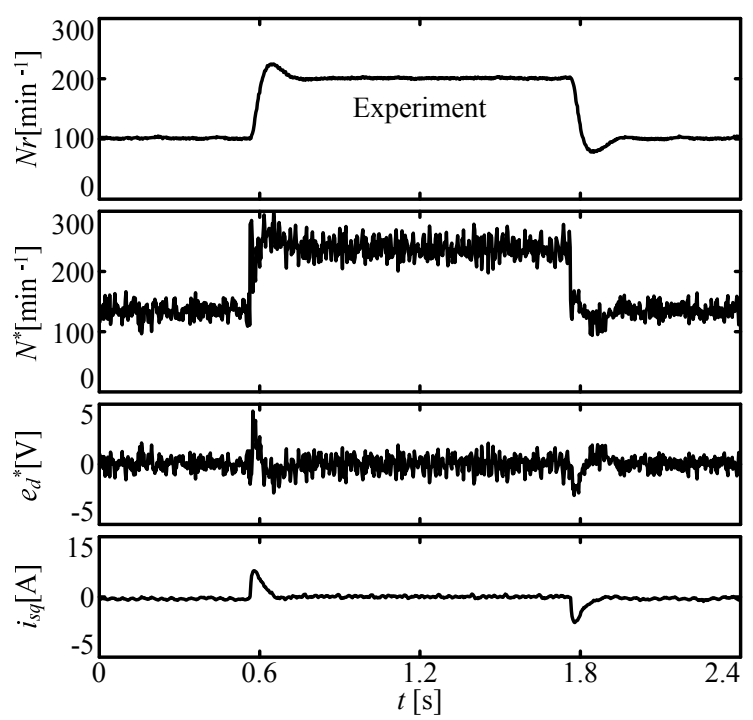

(a) $K_{p c}=0.0$
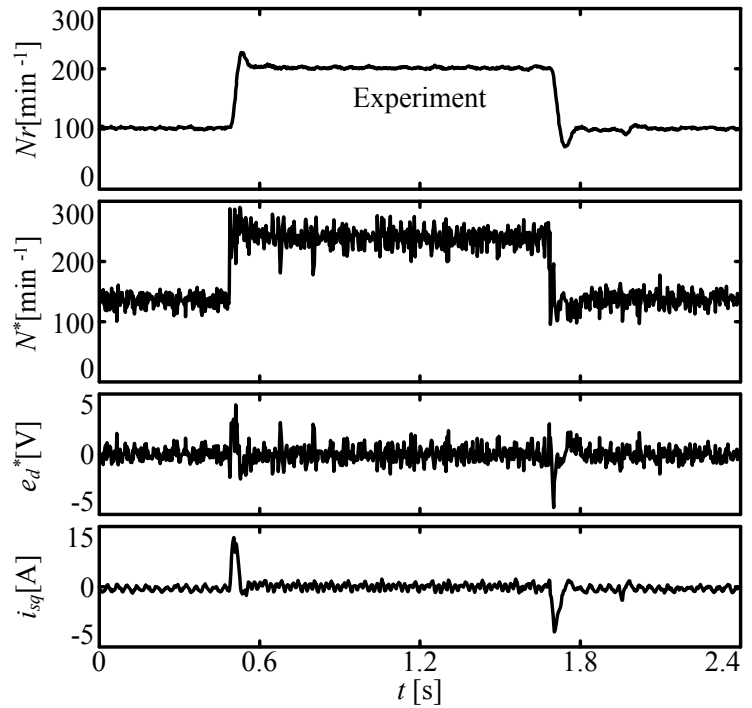

(b) $K_{p c}=1.0$

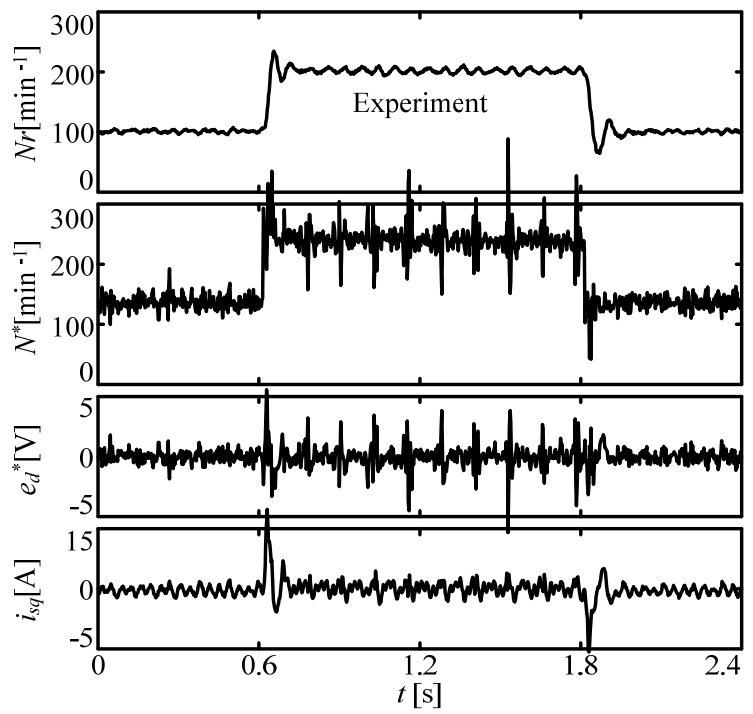

(c) $K_{p c}=2.0$

$\left(100 \rightarrow 200 \rightarrow 100 \mathrm{~min}^{-1}, T_{L}=4 \mathrm{~N}-\mathrm{m},\left|K_{\omega}\right|=5.0, K_{i c}=20.0\right)$. Fig.7. Transient responses of experimental system. 


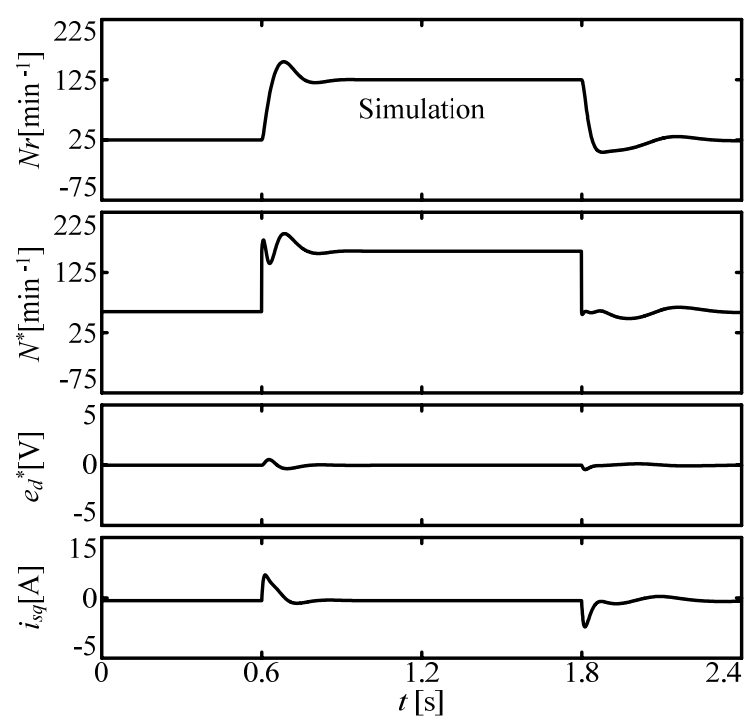

(a) $K_{p c}=0.0$
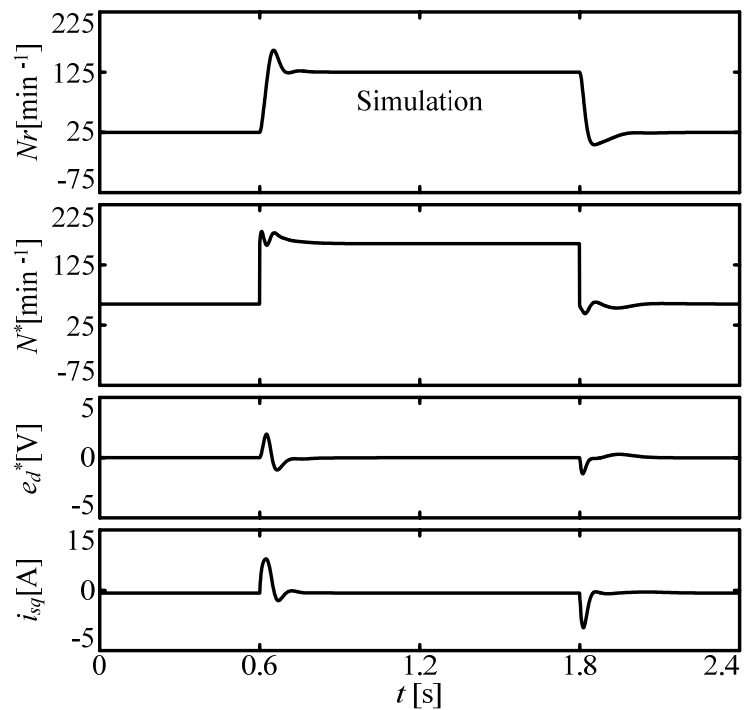

(b) $K_{p c}=1.0$
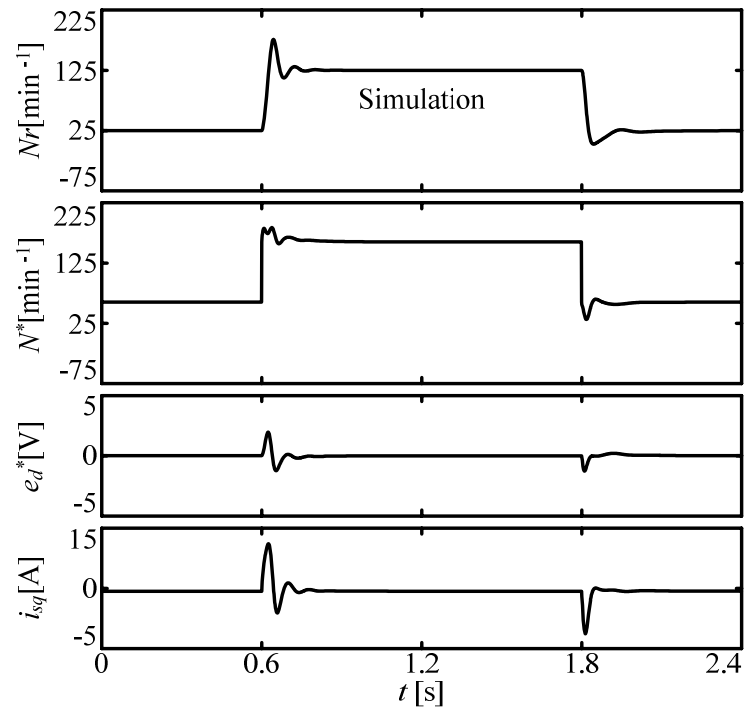

(c) $K_{p c}=2.0$

$\left(25 \rightarrow 125 \rightarrow 25 \mathrm{~min}^{-1}, T_{L}=4 \mathrm{~N}-\mathrm{m},\left|K_{\omega}\right|=5.0, K_{i c}=20.0\right)$. Fig.8. Transient responses of non-linear model.

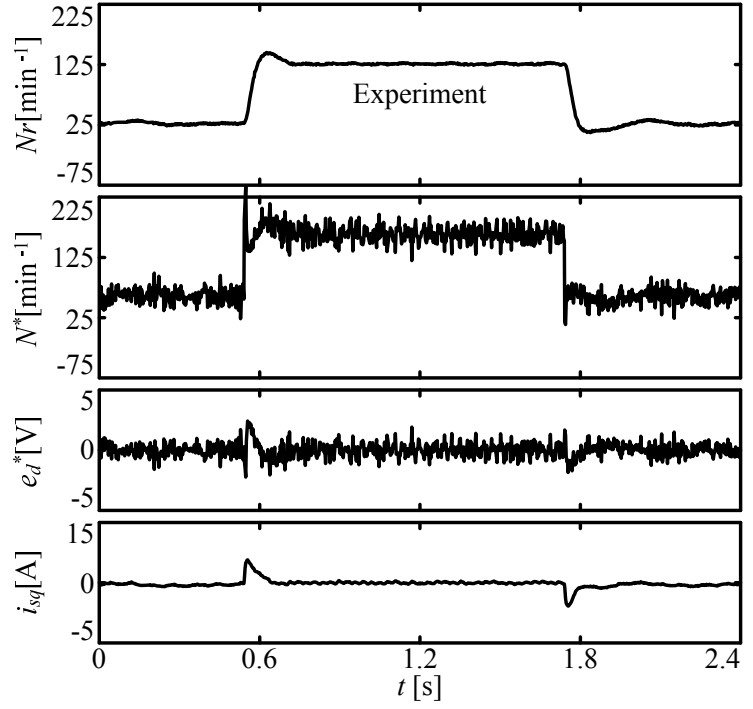

(a) $K_{p c}=0.0$
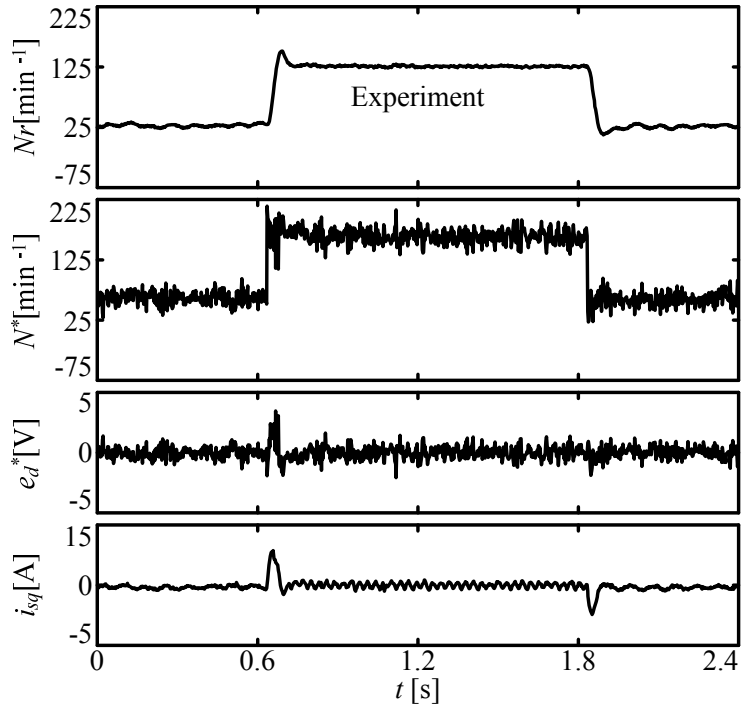

(b) $K_{p c}=1.0$
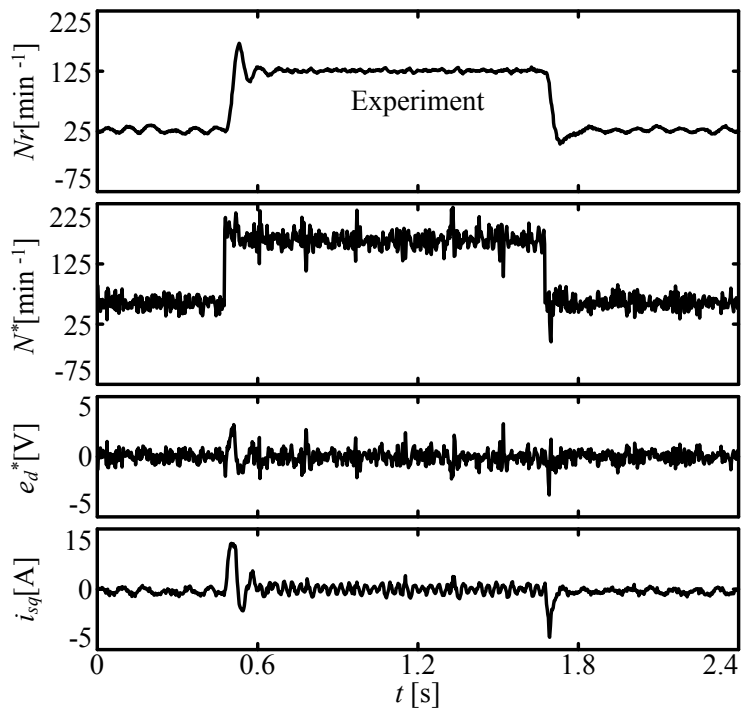

(c) $K_{p c}=2.0$

$\left(25 \rightarrow 125 \rightarrow 25 \mathrm{~min}^{-1}, T_{L}=4 \mathrm{~N}-\mathrm{m},\left|K_{\omega}\right|=5.0, K_{i c}=20.0\right)$.

Fig.9. Transient responses of experimental system. 